\title{
Impact of prepartum body condition score loss on metabolic status during the transition period and subsequent fertility in Brown Swiss dairy cows
}

\author{
Hatice Esra Çolakoğlu ${ }^{1}$, Murat Onur Yazlık ${ }^{1}$, Mert Pekcan², Ufuk Kaya ${ }^{3}$, Cihan Kaçar ${ }^{4}$, \\ Mehmet Rifat Vural ${ }^{1}$, Serdal Kurt ${ }^{1}$, Merve Menekse Yildirim ${ }^{1}$, Ahmet Bas ${ }^{5}$, Şükrü Küplülü ${ }^{1}$ \\ ${ }^{1}$ Department of Obstetrics and Gynecology, ${ }^{2}$ Department of Biochemistry, ${ }^{3}$ Department of Biostatistics, \\ Faculty of Veterinary Medicine, Ankara University, 06110, Ankara, Turkey \\ ${ }^{4}$ Department of Obstetrics and Gynecology, Faculty of Veterinary Medicine, \\ Kafkas University, 36100, Kars, Turkey \\ ${ }^{5}$ Directorate General of Agricultural Enterprises, 06420, Ankara, Turkey \\ yazlik@ankara.edu.tr
}

Received: December 19, 2018 Accepted: July 2, 2019

\begin{abstract}
Introduction: The objectives of this study were to determine the role of a fall in pre-calving body condition score (BCS) in postpartum metabolic status and reproductive outcomes, and gauge the indicativeness of blood metabolites during the transition period. Material and Methods: Cows were grouped based on BCS loss between days $-14 \pm 3$ and 0 relative to calving. Cows that lost no BCS were the BCS control group (BCS-C), cows that lost 0.25 BCS points the low BCS loss group (BCS-L), and those that lost 0.5 points or more the high BCS loss (BCS-H) group. Blood was taken on days $-14 \pm 3,3,14$, and $30 \pm 4$ for determination of comprehensive metabolic panel biomarker levels. Beta-hydroxybutyric acid (BHBA) levels were quantified on postpartum examination days. Vaginal discharge scores, ovarian activity on day $30 \pm 4$, and subsequent fertility parameters were evaluated. Results: The BCS-H cows had lower mean Ca concentrations before calving and on day 3, when the group's BHBA and CK were higher $(\mathrm{P}<0.05)$; on day 14 they had higher AST concentrations $(\mathrm{P}<0.05)$. The BCS-L cows had greater bilirubin levels $(\mathrm{P}<0.05)$. The BCS-H cows had lower cyclicity and higher endometritis rates. First service pregnancy rates were $50 \%, 50 \%$, and $61.9 \%$, open days $96.8,95.75$, and 89.2 , and overall pregnancy rates $56.25 \%, 65 \%$, and $80.95 \%$ in the BCS-H, BCS-L, and BCS-C groups, respectively. Conclusion: Prepartum BCS loss of $\geq 0.5$ points could be associated with Brown Swiss cow low Ca and BHBA concentrations early postpartum, and with subsequent uterine health and overall pregnancy rate. Prepartum Ca concentration might be a prognostic biomarker for postpartum metabolic status and reproductive outcomes.
\end{abstract}

Keywords: cow, pregnancy, body condition score, metabolites.

\section{Introduction}

The most critical period for a dairy cow is called the transition period and lasts 21 days before and 21 after parturition. During the transition period, dairy cows adapt to numerous hormonal and metabolic changes related to the end of pregnancy and the beginning of lactation $(7,14)$. Approximately $50 \%$ of cows suffer from various metabolic, nutritional, and infectious disorders $(23,27)$.

Cows may experience reduced dry matter intake during the close-up period, which generally results in negative energy balance. A pre- or post-partum negative energy balance directly alters the metabolic status of dairy cows (35). An energy requirement due to energy deficiency in the transition period causes fat mobilisation and a consequent increase in non-esterified fatty acids (NEFA) in the blood (30). Excessive concentrations of NEFA in the blood might be toxic (1) because the ruminant liver has insufficient ability to metabolise all NEFA into triacylglycerol. Therefore, ketone bodies are seen in the blood, urine, or in milk when the metabolic efficiency of the liver is overmatched $(1,13)$. The predominant form of ketone bodies in the blood is $\beta$-hydroxybutyric acid (BHBA) which reflects the fatty acid oxidation and energy status of the dairy cow $(10,40)$. Besides illuminating energy status, excessive concentrations of NEFA and BHBA 
have a negative effect on immune cell functions, such as impairing respiratory burst activity (37) and chemotaxis (39). Not only the energy problem but also ion deficiencies are important detriments seen during the transition period and as postpartum effects on dairy cow health $(24,31)$. Calcium is an important ion used in metabolic processes during the transition period to produce good quality colostrum and subsequently milk (31). Most cows suffer from clinical or subclinical hypocalcaemia during the first days of lactation, and total plasma calcium levels reach their physiological level 2 to 3 days after parturition $(17,32)$. Clinical or subclinical hypocalcaemia negatively affects energy metabolism and the immune status of cows and a variable degree of $\mathrm{Ca}$ insufficiency impairs leukocyte activity (24).

The body condition score (BCS) is a useful and simple method to assess an animal's energy reserves (16) as an indirect measurement of fat metabolism and its correlation with energy metabolism (12). The incidence of metabolic disorders and their relationship with BCS has been studied since BCS relates to the fertility status of dairy cows $(4,16,38)$.

It is known that serum metabolites, calcium concentrations and BCS alter during early lactation. The relationship of blood metabolites and ions to the degree of BCS loss during the dry period may provide important information for herd management and reproduction (21). Prepartum BCS loss has been investigated in a few papers, however its consequences on pre- and postpartum period are still not known perfectly $(21,35)$. We hypothesised that pre-calving BCS loss alters calcium and serum metabolites as well as fertility in Brown Swiss dairy cows. The objective of this study was to determine the role of pre-calving BCS loss level in postpartum metabolic status and reproductive outcomes.

\section{Material and Methods}

Animals, housing, and diets. Fifty-seven commercial dairy herd Brown Swiss pre-calving animals with $6,000 \mathrm{~kg}$ average milk yield each were used in this study. The applied dry period was an average of 60 days. Cows were housed together in the last three weeks of pregnancy. As animals demonstrated signs of the approaching parturition, they were moved to calving pens with straw bedding and stayed there until one day after parturition. Then the cows were moved to another pen and stayed there until five days postpartum. Thereafter all animals were housed together for four weeks and then separated according to individual milk yields. The cows had free access to drinking water and feed. Prepartum and postpartum cows were fed total mixed ration (TMR) twice daily for ad libitum intake (Table 1). TMR was provided daily by vertical mixer feeder and offered three times at 09.00, 16.00, and $00.00 \mathrm{~h}$ with diet portions equally split between the three feedings. The barns were naturally ventilated and had artificial lighting. The farm milked nearly 1,000 cows twice daily in a double 48-stall milking parlour. The cows recruited into the study were also milked twice daily at 08:00 and 20:00 during the postpartum period. An individual herd health profile based on serology confirmation for all cows was negative for infectious bovine rhinotracheitis, bovine viral diarrhoea, tuberculosis, and brucellosis. Presync, Ovsynch, and visual oestrus detection combinations were used for farm reproductive management.

Experimental design. First, second, and third or later parity cows were included in the study. Animals were enrolled to the study $14 \pm 3$ days prior to the expected parturition date, and placed into one of three groups according to the BCS change. The cows which maintained their BCS between days $14 \pm 3$ and 0 were allocated to the BCS control group (BCS-C, $n=21$ ), cows which lost $0.25 \mathrm{BCS}$ points were allocated to the low BCS loss (BCS-L, $n=20$ ) group, and cows which lost 0.5 or more BCS points were allocated to the high BCS loss (BCS-H, $n=16)$ group. Animal health status, fertility parameters in the postpartum period, and blood ion and metabolite concentrations were analysed.

Serum concentrations of metabolites and ions. Blood samples were collected from the coccygeal artery or vein into evacuated tubes without anticoagulant at $-14 \pm 3,3,14$, and $30 \pm 4$ days by the same person. Samples were clotted and then placed on ice until processing. Within one hour, the samples were centrifuged $(3,000 \times g, 15 \mathrm{~min})$, and serum samples transferred into new tubes and frozen at $-20^{\circ} \mathrm{C}$ until analysis. NEFA, alkaline phosphatase (ALP), alanine aminotransferase (ALT), aspartate aminotransferase (AST), total bilirubin (BIT), direct bilirubin (BID), $\gamma$-glutamyl transferase (GGT), creatinine kinase (CK), cholesterol, glucose, urea, lactate dehydrogenase $(\mathrm{LDH})$, albumin, total protein, triglyceride, $\mathrm{Ca}$, and $\mathrm{P}$ concentrations were measured on pre- and postpartum sampling days to assess the ion, energy, and enzyme status of the animals. Serum BHBA concentration was measured on days 3, 14, and $30 \pm 4$ post-calving. Commercial kits were used for determination of serum NEFA (NEFA-C Kit; Wako Diagnostics, USA) and BHBA concentrations (Wako Autokit 3-HB; Wako Diagnostics) according to the manufacturer's instructions. Serum samples were analysed for concentrations of Ca, ALP, ALT, AST, BIT, BID, GGT, $\mathrm{CK}$, cholesterol, $\mathrm{P}$, glucose, urea, $\mathrm{LDH}$, albumin, total protein and triglyceride using an XL 600 autoanalyser (Erba, Germany). Negative energy balance was defined using pre- and postpartum measurements of glucose. Metabolite concentrations were as follows: prepartum $\mathrm{NEFA} \geq 0.3 \mathrm{mEq} / \mathrm{L}$, postpartum NEFA $\geq 0.7 \mathrm{mEq} / \mathrm{L}$ (28), and postpartum $\mathrm{BHBA} \geq 1,000 \mu \mathrm{mol} / \mathrm{L}$ (25). Cows which had at least one blood sample with BHBA concentration $>1,000 \mu \mathrm{mol} / \mathrm{L}$ were considered to have subclinical ketosis. Subclinical hypocalcaemia was defined based on serum total $\mathrm{Ca}$ concentration. The cutoff point of serum Ca level was determined as $\leq 8.6 \mathrm{mg} / \mathrm{dl}$ for subclinical hypocalcaemia (24). 
Vaginal mucus score and ovarian cyclicity. Resumption of ovarian cyclicity in the postpartum period was evaluated on day $30 \pm 4$ postpartum by ultrasonography (CTS-800 equipped with a $6.5-9.5 \mathrm{MHz}$ linear probe, SIUI, China). Cows with at least one corpus luteum recorded on that day were considered to be cyclic, whereas those without visible corpus luteum were considered anovulatory. On the same day as reproductive tract examination, the vaginal discharge score was also evaluated by the same person. The vulvae were cleaned with a disinfected paper towel. The walls of the vagina and external os of the cervix were palpated with a lubricated clean-gloved hand, and mucus contents of the vagina were removed manually for examination. The vaginal mucus was assessed with the method of Sheldon et al. (36) $(0=$ clear or translucent mucus, $1=$ mucus containing flecks of white or off-white pus, 2 = mucus containing $\leq 50 \%$ white or off-white mucopurulent material, and $3=$ discharge containing $>50 \%$ purulent material). Animals that had a vaginal discharge score $\geq 2$ were diagnosed as suffering from clinical endometritis.

Fertility. Cows which had the corpus luteum received $5 \mathrm{~mL}$ of PGF2 $\alpha$ (Enzoprost; Ceva, France) intramuscularly on the $30^{\text {th }}$ day postpartum. Cows which showed clinical signs of oestrus were inseminated 45 days post-calving observing the a.m.-p.m. rule. Cows which did not show any clinical signs of oestrus until 75 days postpartum received a timed breeding programme. Cows received $2 \mathrm{~mL}$ of GnRH (Ovarelin; Ceva, France) intramuscularly. Seven days later the cows received $5 \mathrm{~mL}$ of PGF $2 \alpha$ intramuscularly. Then the cows received the $2^{\text {nd }}$ dose of GnRH 48 hours after PGF2 $\alpha$. The cows were inseminated $12 \mathrm{~h}$ after the $2^{\text {nd }}$ GnRH injection. Each cow which showed clinical signs of oestrus between injections was inseminated. Thirty days after inseminations, cows were examined by transrectal ultrasonography to identify the presence of an embryonic heartbeat. All pregnant cows were re-examined 60 days after the last insemination to determine pregnancy loss. Non-pregnant cows re-entered the timed breeding programme. For evaluation of fertility, the following measures were used: number of cows pregnant after the first artificial insemination in relation to the total number of cows inseminated as a percentage (referred to as the first service conception rate), interval from calving to conception (referred to as days open), and number of pregnant cows at 150 days postpartum in relation to the number of all cows inseminated until that date as a percentages (referred to as pregnancy on day 150 postpartum).

Body condition score. On days of blood sampling, body condition scores were determined by one person on the 5-point scale in 0.25 -unit increments as described by Ferguson et al. (9).

Statistical analysis. Before performing the statistical analysis, data were examined with the Shapiro-Wilk test for normality and Levene's test for homogeneity of variances as parametric test assumptions. Descriptive statistics for each variable were calculated and presented as mean \pm standard error of mean (SEM). The Pearson correlation coefficient was used to determine the correlation between variables (BIT, BID, AST, ALP, ALT, GGT, CK, cholesterol, glucose, urea, LDH, albumin, total protein, triglyceride, NEFA, BHBA, P, and Ca) for each time of sampling. Correlations were considered strong, moderate, and weak when $\mathrm{r}>0.5, \mathrm{r}=0.31-0.5$, and $\mathrm{r}<0.3$, respectively. The chi-squared test was used to compare the groups in terms of pregnancy rates, presence of the corpus luteum, and clinical endometritis. The calving to conception interval was analysed with the KruskalWallis test.

The following model was used for evaluating the effect of the group, day of sampling and their interaction with BCS, BIT, BID, AST, ALP, ALT, GGT, CK, cholesterol, glucose, urea, $\mathrm{LDH}$, albumin, total protein, triglyceride, NEFA, BHBA, P, and Ca:

$Y_{i j k}=\mu+G_{i}+D_{j}+(G \times D)_{i j}+e_{i j k}$

$Y_{i j k}$ : the dependent variable

$\mu$ : the overall mean

$G_{i}$ : effect of the group ( $i=$ BCS-H cows, BCS-L cows, and BCS-C cows)

$D_{j}$ : effect of the day of sampling $\left(D_{j}=-14 \pm 3,3\right.$, 14 , and $30 \pm 4 \mathrm{~d})$

$(G \times D)_{i j}$ : the interaction between the group $(i)$ and the day of sampling $(j)$

$e_{i j k}$ : residual error.

Animals within groups were assessed as a random effect, while group, period, or day of sampling and their interaction were assessed as fixed effects. When a significant difference was revealed, any significant terms were compared by simple effect analysis with Bonferroni adjustment. $\mathrm{P}<0.05$ was considered significant in all analyses. All data were analysed using the mixed procedure of SPSS (V22.0; IBM SPSS, USA).

\section{Results}

The number of parities was not statistically significantly different between groups. The mean age of production was 2.2 lactations.

Body condition scores changed over time in all groups $(\mathrm{P}<0.05)$. The changes during the study period are shown in Fig. 1. The mean BCS was significantly higher in BCS-C cows compared to BCS-L and BCS-H animals after parturition $(\mathrm{P}<0.05)$.

The concentrations of AST, ALP, cholesterol, BIT, $\mathrm{BID}$, glucose, urea, total protein, $\mathrm{Ca}$, triglyceride, and NEFA changed over time in all groups $(\mathrm{P}<0.05)$. However, regardless of the group, no significant difference was observed in BHBA, albumin, LDH, P, ALT, CK, or GGT as the study advanced $(\mathrm{P}>0.05)$.

Prepartum blood sampling showed that the mean $\mathrm{Ca}$ levels of BCS-H cows were in the subclinical hypocalcaemia range $(8.4 \pm 0.2 \mathrm{mg} / \mathrm{dl})$. On the third day postpartum, $\mathrm{Ca}$ concentration was greater in BCS-C than BCS-H $(\mathrm{P}<0.05)$ cows, but the BCS-H and BCS-L groups had similar $\mathrm{Ca}$ concentrations $(\mathrm{P}>0.05)$. 
Mean blood $\mathrm{Ca}$ concentrations were at subclinical hypocalcaemia levels in BCS-L and BCS-H cows (Fig. 2).

Whereas BHBA levels were different during the postpartum period, NEFA concentration was similar among groups during the study period (not shown in table). None of the cows included in the study had a severe negative energy balance effect as indicated by NEFA values. On the other hand, the BCS-L and BCS-C groups showed similar blood BHBA concentrations during the study period, but the BCS-H group showed greater BHBA levels on days $3(1,378 \pm 317 \mu \mathrm{mol} / \mathrm{L})$ and $30 \pm 4(1,216 \pm 273 \mu \mathrm{mol} / \mathrm{L})$ postpartum (Fig. 3). The concentrations of BHBA on these days were at subclinical ketosis level. For BCS-H cows, NEFA concentration and BHBA levels showed moderate correlation on day $3(\mathrm{r}=0.365 ; \mathrm{P}<0.05)$ and strong correlation on days $14(\mathrm{r}=0.755 ; \mathrm{P}<0.05)$ and $30 \pm 4$ $(\mathrm{r}=0.776 ; \mathrm{P}<0.05)$, and these parameters were also negatively correlated with $\mathrm{Ca}$ content $(\mathrm{r}=-0.591$; $\mathrm{P}<0.05)$ in prepartum.
Glucose, urea, LDH, ALT, albumin, total protein, cholesterol, triglyceride, and $\mathrm{P}$ levels were similar among the groups (not shown in table).

Aspartate aminotransferase, an enzyme for liver damage detection, was higher in the BCS-H group than in other groups at 14 days postpartum $(\mathrm{P}<0.05)$. This group also had greater $\mathrm{CK}$ concentration on the third day postpartum, and AST concentration showed a positive strong correlation with $\mathrm{CK}$ levels $(\mathrm{r}=0.641 ; \mathrm{P}<0.05)$. On day 3 postpartum in the BCS-L group, BID and BIT values were greater than in $\mathrm{BCS}-\mathrm{C}$ cows. The high level of BIT concentration was also sustained at 14 days postpartum $(\mathrm{P}<0.05$; Table 2$)$.

Postpartum genital tract examination, clinical endometritis rate, and fertility parameters are shown in Table 3. BCS-C cows had a high proportion of ovarian resumption at $30 \pm 4$ days postpartum and fewer days open (89.2 days). Also, BCS-C cows had a significantly lower clinical endometritis rate $(9.5 \%)$, and higher overall pregnancy rate $(80.95 \%)$ than the $\mathrm{BCS}-\mathrm{H}$ and BCS-L groups $(\mathrm{P}=0.032$ and $\mathrm{P}=0.035$, respectively).

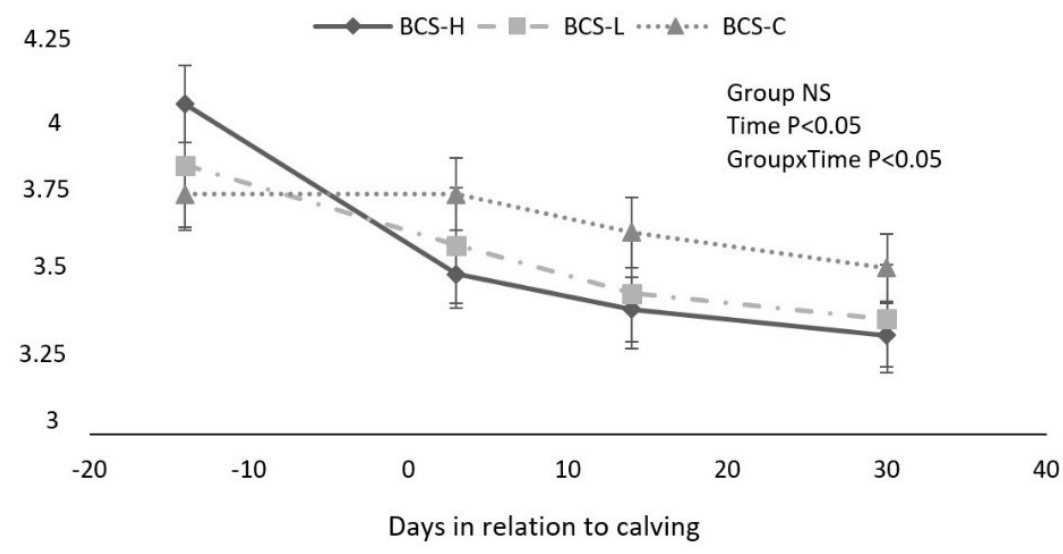

Fig. 1. BCS changes (mean \pm SEM) during the study period among groups

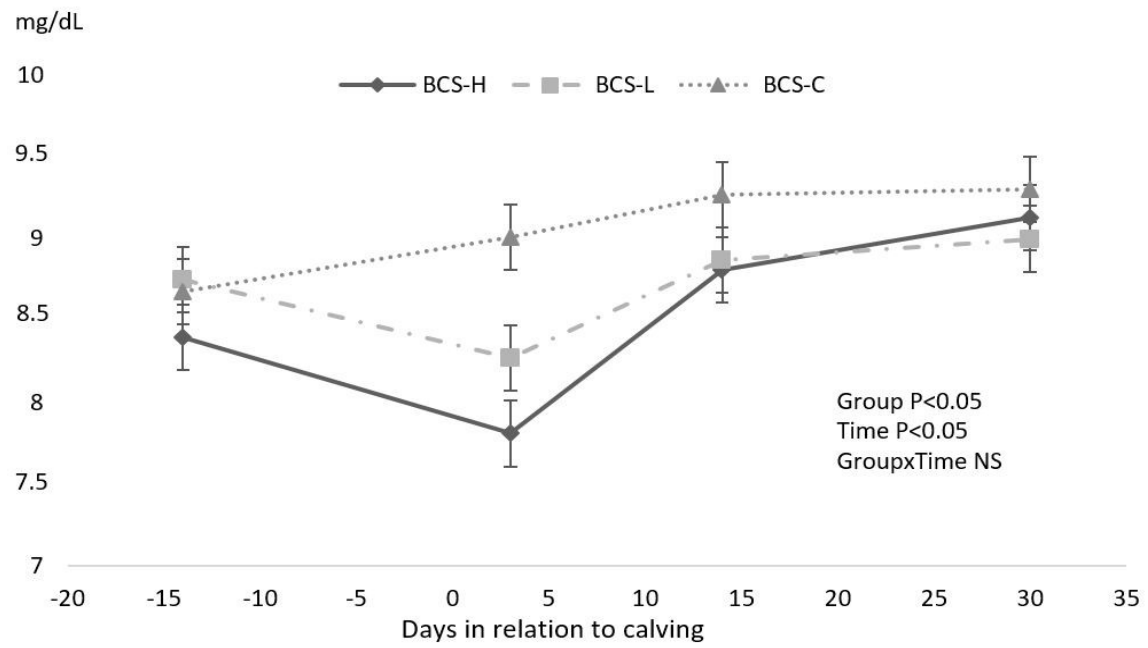

Fig. 2. Effect of different body condition score (BCS) loss on concentration of $\mathrm{Ca}$ (mean $\pm \mathrm{SEM}$ ) 
Table 1. Constituents of diets fed during far-off ( -50 to -31 days relative to expected calving), close-up ( -30 days to calving), and early lactation

\begin{tabular}{|c|c|c|c|}
\hline Component & Far-off & Close-up & Early lactation \\
\hline \multicolumn{4}{|l|}{ Ingredient, $\%$ of DM } \\
\hline Vetch hay & 11.58 & - & - \\
\hline Alfalfa silage & - & - & 9.67 \\
\hline Alfalfa hay & 7.89 & 6.97 & 10.29 \\
\hline Corn silage & 52.60 & 43.51 & 44.16 \\
\hline Wheat straw & 10.52 & 22.25 & - \\
\hline Soybean meal, $48 \% \mathrm{CP}$ & - & - & 1.61 \\
\hline Concentrated feed & 15.78 & 20.94 & 30.31 \\
\hline Limestone & 0.82 & 2.25 & 1.57 \\
\hline Salt & 0.30 & - & 0.26 \\
\hline Ammonium chloride & - & 1.15 & - \\
\hline Dicalcium phosphate & 0.14 & 0.30 & 0.44 \\
\hline Magnesium oxide & - & 0.12 & 0.44 \\
\hline Magnesium sulphate & 0.16 & 1.35 & 0.25 \\
\hline Sodium bicarbonate & - & - & 0.70 \\
\hline Calcium sulphate & - & - & 0.10 \\
\hline Mineral-vitamin $\operatorname{mix}^{1}$ & 0.21 & 0.17 & 0.20 \\
\hline
\end{tabular}

Diet contained a minimum $4.3 \%$ of $\mathrm{Mg}, 8 \%$ of $\mathrm{S}, 6.1 \%$ of $\mathrm{K}, 2.0 \%$ of $\mathrm{Fe}, 3.0 \%$ of $\mathrm{Zn}, 3.0 \%$ of $\mathrm{Mn}$, $5,000 \mathrm{mg} / \mathrm{kg}$ of Cu, $250 \mathrm{mg} / \mathrm{kg}$ of I, $40 \mathrm{mg} / \mathrm{kg}$ of Co, $150 \mathrm{mg} / \mathrm{kg}$ of Se, $2,200 \mathrm{kIU} / \mathrm{kg}$ of vitamin A, $660 \mathrm{kIU} / \mathrm{kg}$ of vitamin $\mathrm{D}_{3}$, and 7,700 IU/kg of vitamin $\mathrm{E}$

Table 2. Effect of different body condition score (BCS) changes on concentrations of AST, CK, GGT, cholesterol, BID, and BIT (mean \pm SEM) among groups

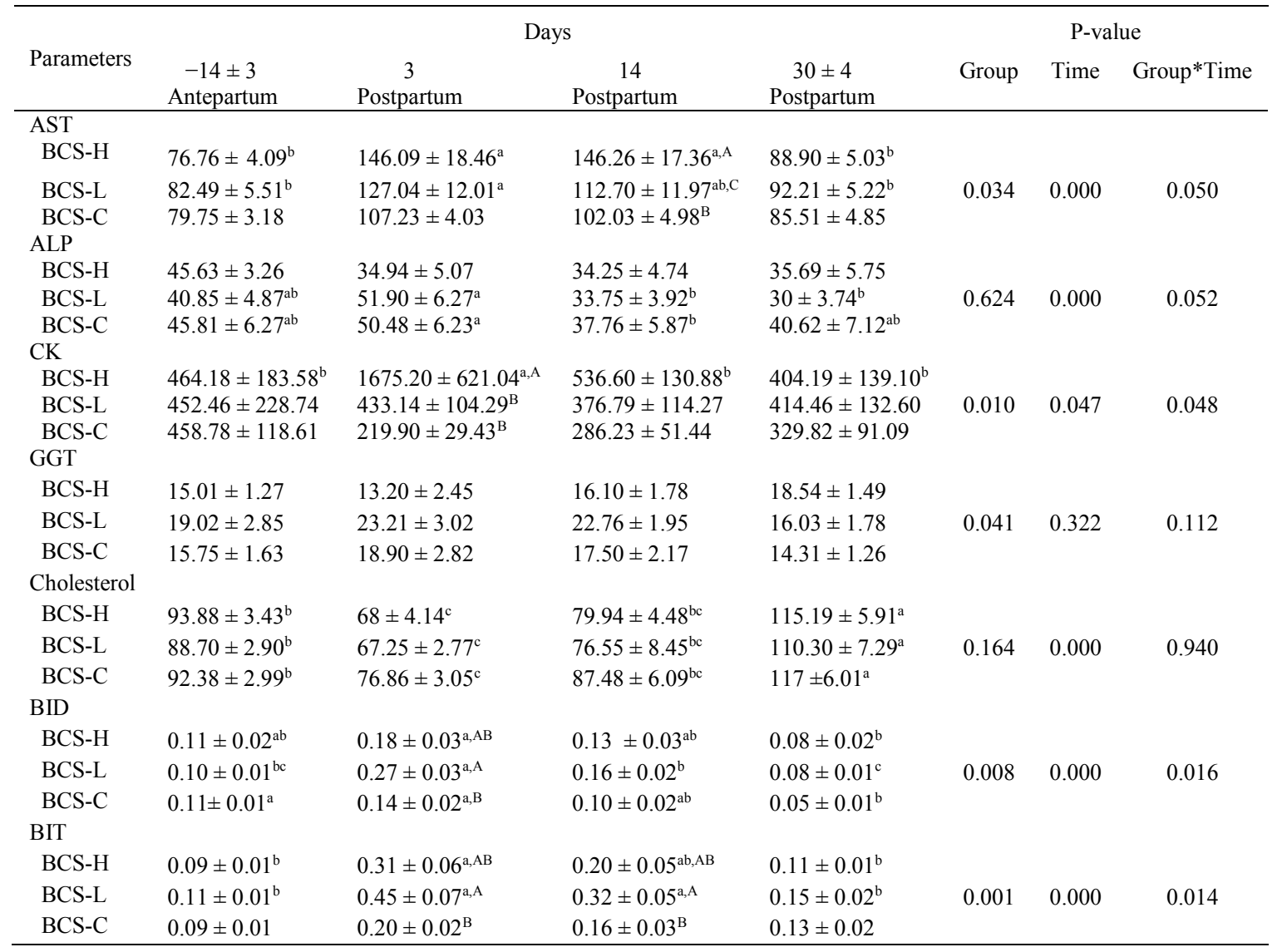

Means within a row $(\mathrm{a}-\mathrm{c})$ and column $(\mathrm{A}-\mathrm{B})$ with different superscript letters differ significantly $(\mathrm{P}<0.05)$ 
Table 3. Effect of different body condition score (BCS) changes on rate of the corpus luteum activity, clinical endometritis, calving to conception interval (median (min-max)), and pregnancy rate

\begin{tabular}{lllll}
\hline Parameter & \multicolumn{2}{c}{ Group } & BCS-H & P-value \\
\hline Corpus luteum activity $<30 \pm 4 \mathrm{~d}(\%)$ & BCS-C & BCS-L & 50 & 0.187 \\
Clinical endometritis (\%) & 61.90 & 40 & $37.50^{\mathrm{a}}$ & 0.032 \\
Interval from calving to conception (day) & $9.50^{\mathrm{b}}$ & $35^{\mathrm{a}}$ & $106(47-150)$ & 0.561 \\
Pregnancy rate (\%) & $82(47-119)$ & $122(50-168)$ & & \\
$1^{\text {st }}$ service & & & 50 & 0.473 \\
Overall & 61.90 & 50 & $56.25^{\mathrm{b}}$ & 0.035 \\
\hline
\end{tabular}

Means within a row $(a, b)$ with different superscript letters differ significantly $(\mathrm{P}<0.05)$

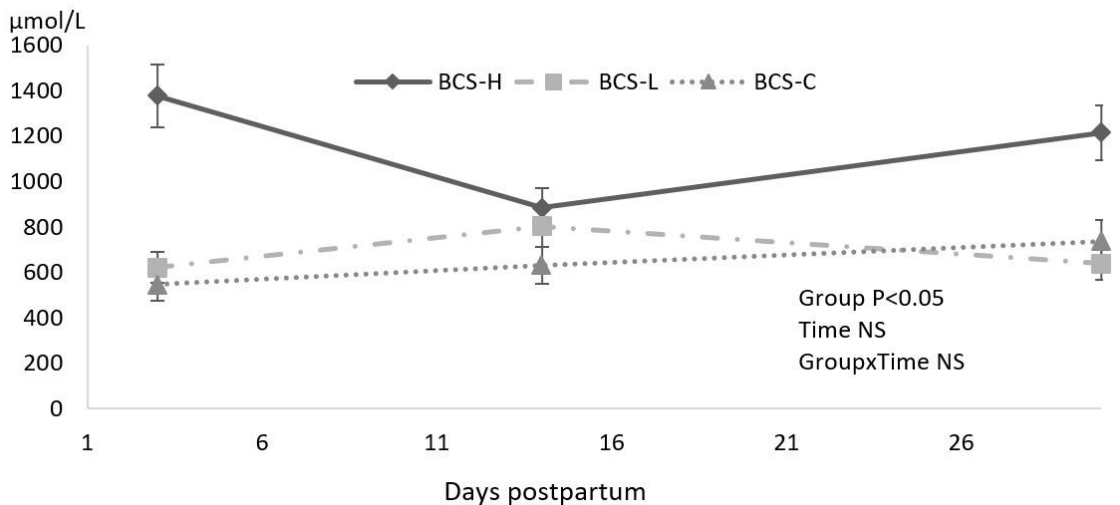

Fig. 3. Effect of different body condition score (BCS) changes at peripartum period on BHBA

\section{Discussion}

Body condition score loss depends on many factors starting with the genotype of the cow and ending with farm management. BCS loss during the last weeks of the dry period may depend on mistakes made during transition period management which may include inadequate nutrition or controlled energy feeding strategies $(6,35)$. Pre-partum BCS loss has been investigated in a few papers; however, its consequences for the pre- and postpartum periods are still not perfectly known $(21,35)$.

Prepartum BCS loss has no role in prepartum blood concentrations; however, it does have one in determining metabolic and ion status in the postpartum period (35). High NEFA concentration has a negative effect on reproduction (22) and health status in dairy cows (12). The results of energy-controlled feeding studies do not refer to the exact consequences on prepartum serum NEFA concentrations (3, 20). Although in our study we did not observe any significant difference between groups in NEFA concentrations in prepartum and postpartum examinations, NEFA concentration increased similarly on three days postcalving. All cows were on the same farm and fed the same TMR during the study period. It was clearly shown that the energy in the feed ration had no role in prepartum BCS loss.

Concentrations of NEFA increased after parturition and then started to decline dramatically until $30 \pm 4$ days postpartum; however, there was no difference between groups. It is known that increased NEFA concentration is followed by a decrease in dry matter intake. Combined with that, energy demands for milk production increase. Whereas the liver has limited capacity for fatty acid oxidation and at the end of the limit, ketone bodies accumulate. As a result of that process, clinical or subclinical ketosis might be seen during early lactation (33). This information is supported by the present study. BCS-H cows suffered from subclinical ketosis at one week $(1,378.34 \pm 317.29 \mu \mathrm{mol} / \mathrm{L})$ and four weeks $(1,216.04 \pm 273.86 \mu \mathrm{mol} / \mathrm{L})$ postpartum. McCarthy et al. (26) suggested that there is a weak relationship between NEFA and BHBA concentrations. Therefore, the possible reason for the high BHBA concentration in the BCS-H group might be the higher prepartum body condition score (mean BCS of $4.03 \pm 0.08$ on day $-14 \pm 3)$

Postpartal metabolic tests showed that cows in the BCS-H group suffered from high mean BHBA levels at 3 and $30 \pm 4$ days after parturition. A high concentration of BHBA is related to weaker immune response (23) and lower reproductive parameters (22). Roche et al. (33) explained however that it is hard to determine the causes of BCS loss or its effects on uterine infections. Impaired immune response in the early postpartum period under the effect of increased BHBA might be responsible for suppressing the activity of bacterial clearance during the early puerperal period and for any subsequent clinical endometritis. Sheehy et al. (35) reported that prepartum BCS loss resulted in high BHBA concentration at one week and four weeks after calving. 
The present study suggested that a BCS loss of 0.5 points or greater during the close-up period had a negative influence on calcium balance in the prepartum and early postpartum period. The mean calcium concentrations at $-14 \pm 3$ and 3 days were at subclinical hypocalcaemia level in the BCS-H group $(8.40 \pm 0.20 \mathrm{mg} / \mathrm{dl}$ and $7.81 \pm 0.33 \mathrm{mg} / \mathrm{dl}$, respectively). Sheehy et al. (35) and Østergaard et al. (29) stated that Ca concentration at calving could be used as a biomarker of energy status. Furthermore, we suggest that the measurement of $\mathrm{Ca}$ rather than NEFA concentration three days postpartum could relate to the postpartum metabolic and reproductive outcomes.

The blood AST levels in the BCS-H group were significantly higher on days 3 and 14 postpartum and correlated with $\mathrm{CK}$ at 3 days postpartum $(\mathrm{r}=0.641$; $\mathrm{P}<0.05)$. The high level of AST could be associated with higher fat mobilisation and negative energy balance due to increased metabolic demands (5). AST is not a liver-specific enzyme, and muscle damage could also result in an increase in AST levels $(11,15,19)$. CK activity in cows betrays the source releasing AST (liverrelated or muscle-related). The increase in AST levels together with CK reflected that BCS-H cows had muscle loss. The present study also indicated higher total and direct bilirubin concentrations in BCS-L cows than in the BCS-H and BCS-C groups at 3 days postpartum, and significantly higher total bilirubin concentrations at 14 days. When these results were combined with AST concentrations, the related groups were seen not to have suffered any crucial hepatic damage during the study period.

The prepartum high BCS and low Ca levels and postpartum high BHBA concentration might be responsible for reduced dry matter intake (34), suppressed bacterial clearance ability in the early puerperal period, subsequent clinical endometritis occurrence (33), and predisposition to periparturient metabolic disorders such as ketosis, milk fever, displacement of abomasum, retained fetal membranes, etc. (8).

In BCS-H and BCS-L cows, although the resumption of ovarian activity at $30 \pm 4$ days postpartum was delayed and resulted in more days open compared to the BCS-C group, the differences were not statistically significant (Table 3 ). But these groups had a significantly higher rate of clinical endometritis and lower overall pregnancy rate $(56.25 \%$ and $65 \%$, respectively) than the BCS-C group (overall pregnancy rate $80.9 \%$ ). These results agree with Hoedemaker et al. (16) who reported that cows which lost weight during the dry period had longer durations of days open and lower pregnancy rates at 200 days in milk. Janus et al. (18) associated the postpartum fertility problem with high BCS before parturition. It was similar to the present study in which a decreased pregnancy rate was shown in BCS-H cows. The exact mechanism underlying the changes in fertility parameters is unknown. However, some different theories exist like reduced functional competence of ovulating follicles and subtle changes in steroid hormone secretion $(2,33)$. The adverse effects of high BHBA concentration remain until four to five weeks after parturition. These adverse effects remain longer in the microenvironment of the uterus and ovaries, for between 60 and 100 days postpartum. This carryover effect triggers fertilityrelated problems (22).

Prepartum BCS loss of 0.5 points or more could negatively affect blood serum $\mathrm{Ca}$ level at pre- and postpartum and postpartum BHBA concentrations in Brown Swiss cows. The subclinical ketosis and subclinical hypocalcaemia in the periparturient period would increase the risk of clinical endometritis on the $30^{\text {th }} \pm 4$ days postpartum, and furthermore would decrease the overall pregnancy rate at 150 days postpartum. Otherwise, the screening of blood $\mathrm{Ca}$ and the monitoring of BCS loss during the last $14 \pm 3$ days of pregnancy and early postpartum period could be useful to identify cows susceptible to metabolic and reproductive problems in the postpartum period.

Conflict of Interests Statement: The authors declare there is no conflict of interests regarding publication of this article.

Financial Disclosure Statement: This work was supported by the Ankara University Scientific Research Projects Coordination Unit (project number: 16B0239001), Ankara, Turkey.

Animal Rights Statement: All procedures involving study animals in the experiment were approved by the Ankara University Institutional Animal Ethics Committee (2015-12-139).

Acknowledgements: All authors thank to Directorate of Anadolu Agricultural Enterprises for their technical support. The preliminary version of this article was accepted for oral presentation at the VI National and I International Congress of the Turkish Society of Veterinary Gynaecology, 12-15 October 2017, Marmaris, Turkey.

\section{References}

1. Adewuyi A.A., Gruys E., Van Eerdenburg F.J.C.M.: Non esterified fatty acids (NEFA) in dairy cattle. A review. Vet Q 2005, 27, 117-126.

2. Beam S.W., Butler W.R.: Effects of energy balance on follicular development and first ovulation in postpartum dairy cows. J Reprod Fertil 1999, 54, 411-424.

3. Cardoso F.C., LeBlanc S.J., Murphy M.R., Drackley J.K.: Prepartum nutritional strategy affects reproductive performance in dairy cows. J Dairy Sci 2013, 96, 5859-5871.

4. Chagas L.M., Bass J.J., Blache D., Burke C.R., Kay J.K., Lindsay D.R., Lucy M.C., Martin G.B., Meier S., Rhodes F.M., Roche J.R., Thatcher W.W., Webb R.: New perspectives on the roles of nutrition and metabolic priorities in the subfertility of highproducing dairy cows. J Dairy Sci 2007, 90, 4022-4032. 
5. Colakoglu H.E., Polat I.M., Vural M.R., Kuplulu S., Pekcan M., Yazlik M.O., Baklaci C.: Associations between leptin, body condition score, and energy metabolites in Holstein primiparous and multiparous cows from 2 to 8 weeks postpartum. Rev Med Vet 2017, 168, 93-101.

6. Dann H.M., Litherland N.B., Underwood J.P., Blonaz M., D’Angelo A., McFaden J.W., Drackley J.K.: Diets during far-off and close-up dry periods affect periparturient metabolism and lactation in multiparous cows. J Dairy Sci 2006, 89, 3563-3577.

7. Drackley J.K.: Biology of dairy cows during the transition period: The final frontier? J Dairy Sci 1999, 82, 2259-2273.

8. Duffield T.: Subclinical ketosis in lactating dairy cattle. Vet Clin North Am Food Anim Pract 2000, 16, 231-253.

9. Ferguson J.D., Galligan D.T., Thomsen T.: Principal descriptors of body condition score in Holstein cows. J Dairy Sci 1994, 77, 2695-2703.

10. Galvão K.N., Flaminio M.J.B.F., Brittin S.B., Sper R., Fraga M., Caixeta L., Gilbert R.O.: Association between uterine disease and indicators of neutrophil and systemic energy status in lactating Holstein cows. J Dairy Sci 2010, 93, 2926-2937.

11. Garry F.B., Fettman M.J., Curtis C.R., Smith J.A.: Serum bile acid concentrations in dairy cattle with hepatic lipidosis. J Vet Intern Med 1994, 8, 432-438.

12. Ghanem M.E., Tezuka E., Sasaki K., Takahashi M., Yamagishi N., Izaike Y., Osawa T.: Correlation of blood metabolite concentrations and body condition scores with persistent postpartum uterine bacterial infection in dairy cows. J Reprod Develop 2016, 62, 457-463.

13. Goff J.P., Horst R.L.: Physiological changes at parturition and their relationship to metabolic disorders. J Dairy Sci 1997, 80, 1260-1268.

14. Grummer R.R.: Impact of changes in organic nutrient metabolism on feeding the transition dairy cow. J Anim Sci 1995, 73, $2820-2833$.

15. Gül Y., Gründer H.D.: Bile acid determination in blood serum and its significance for the diagnosis of liver diseases in cattle. Dtsch Tierarztl Wochenschr 1988, 95, 140-146.

16. Hoedemaker M., Prange D., Gundelach Y.: Body condition change ante- and postpartum, health and reproductive performance in German Holstein cows. Reprod Dom Anim $2009,44,167-173$

17. Horst R.L., Goff J.P., Reinhardt T.A.: Advancing age results in reduction of intestinal and bone 1,25-dihydroxyvitamin D receptor. Endocrinology 1990, 126, 1053-1057.

18. Januś E., Litwińczuk Z.: Dependence of the productivity of cows on their body condition before parturition and at the start of lactation Med Weter 2019, 75, 111-114.

19. Kalaitzakis E., Panousis N., Roubies N., Giadinis N., Kaldrymidou E., Georgiadis M., Karatzias H.: Clinicopathological evaluation of downer dairy cows with fatty liver. Can Vet J 2010, 51, 615-622.

20. Keogh B., French P., McGrath T., Storey T., Mulligan F.J.: Effect of three forages and two forage allowances offered to pregnant dry dairy cows in winter on periparturient performance and milk yield in early lactation. Grass Forage Sci 2009, 64, 292-303.

21. Kim I.H., Suh G.H.: Effect of the amount of body condition loss from the dry to near calving periods on the subsequent body condition change, occurrence of postpartum diseases, metabolic parameters and reproductive performance in Holstein dairy cows. Theriogenology 2003, 60, 1445-1456.

22. Knop R., Cernescu H.: Effects of negative energy balance on reproduction in dairy cows. Lucrări Stiintifice Med Vet 2009, 42, 198-205.
23. LeBlanc S.: Monitoring metabolic health of dairy cattle in the transition period. J Reprod Develop 2010, 56, 29-35.

24. Martinez N., Risco C.A., Lima F.S., Bisinotto R.S., Greco L.F., Ribeiro E.S., Maunsell F., Galvo K., Santos J.E.P.: Evaluation of peripartal calcium status, energetic profile, and neutrophil function in dairy cows at low or high risk of developing uterine disease. J Dairy Sci 2012, 95, 7158-7172.

25. McArt J.A.A., Nydam D.V., Oetzel G.R.: Epidemiology of subclinical ketosis in early lactation dairy cattle. J Dairy Sci 2012, 95, 5056-5066.

26. McCarthy M.M., Mann S., Nydam D.V., Overton T.R., McArt J.A.A.: Concentrations of nonesterified fatty acids and $\beta$-hydroxybutyrate in dairy cows are not well correlated during the transition period. J Dairy Sci 2015, 98, 6284-6290.

27. Mulligan F.J., Doherty M.L.: Production diseases of the transition cow. Vet J 2008, 176, 3-9.

28. Ospina P.A., Nydam D.V., Stokol T., Overton T.R.: Association between the proportion of sampled transition cows with increased nonesterified fatty acids and beta-hydroxybutyrate and disease incidence, pregnancy rate, and milk production at the herd level. J Dairy Sci 2010, 93, 3595-3601.

29. Østergaard S., Srensen J.T., Houe H.: A stochastic model simulating milk fever in the dairy herd. Prev Vet Med 2003, 58, 125-143.

30. Pechova A., Pavlata L.: The use of metabolic profiles in the control of nutrition of dairy cows. In: Nutrition of Cattle in Terms of Production and Preventive Medicine. Edited by R. Dvořák, Noviko, Brno, 2005, pp. 102-111.

31. Ramberg C.F., Mayer G.P., Kronfeld D.S., Phang J.M, Berman M.: Calcium kinetics in cows during late pregnancy, parturition, and early lactation. Am J Physiol 1970, 219, 1166-1177.

32. Reinhardt T.A., Lippolis J.D., McCluskey B.J., Goff J.P., Horst R.L.: Prevalence of subclinical hypocalcemia in dairy herds. Vet J 2011, 188, 122-124.

33. Roche J.R., Friggens N.C., Kay J.K., Fisher M.W., Stafford K.J., Berry D.P.: Invited review: body condition score and its association with dairy cow productivity, health, and welfare. J Dairy Sci 2009, 92, 5769-5801.

34. Roche J.R., Kolver E.S., Kay J.K.: Influence of precalving feed allowance on periparturient metabolic and hormonal responses and milk production in grazing dairy cows. J Dairy Sci 2005, 88 , 677-689.

35. Sheehy M.R., Fahey A.G., Aungier S.P.M., Carter F., Crowe M.A., Mulligan F.J.: A comparison of serum metabolic and production profiles of dairy cows that maintained or lost body condition 15 days before calving. J Dairy Sci 2017, 100, 536-547.

36. Sheldon I.M., Lewis G.S., LeBlanc S., Gilbert R.O.: Defining postpartum uterine disease in cattle. Theriogenology 2006, 65, $1516-1530$

37. Ster C., Loiselle M.C., Lacasse P.: Effect of postcalving serum nonesterified fatty acids concentration on the functionality of bovine immune cells. J Dairy Sci 2012, 95, 708-717.

38. Studer E.: A veterinary perspective of on-farm evaluation of nutrition and reproduction. J Dairy Sci 1998, 81, 872-876.

39. Suriyasathaporn W., Heuer C., Noordhuizen-Stassen E.N., Schukken Y.H.: Hyperketonemia and the impairment of udder defense: a review. BMC Vet Res 2000, 31, 397-412.

40. Wathes D.C., Cheng Z., Bourne N., Taylor V.J., Coffey M.P., Brotherstone S.: Differences between primiparous and multiparous dairy cows in the inter-relationships between metabolic traits, milk yield, and body condition score in the periparturient period. Domest Anim Endocrinol 2007, 33, 203-225. 